\title{
GESTÃO DOS RESÍDUOS E REJEITOS SÓLIDOS INDUSTRIAIS: A CONJUNTURA DOS PÓLOS CALÇADISTAS BRASILEIROS
}

\author{
Elias Antonio Vieira ${ }^{1}$, Agnaldo de Souza Barbosa ${ }^{2}$ \\ ${ }^{1}$ Geógrafo, pós doutorando, pesquisador e bolsista vinculado à FAPESP/LABDES/UNESP, campus Franca, SP, Brasil, \\ evieira371@gmail.com \\ ${ }^{2}$ Doutor em Ciências Sociais e docente da UNESP, campus Franca, SP, Brasil, agnaldoweb@gmail.com
}

http://dx.doi.org/10.5902/223613087643

\section{RESUMO}

Neste estudo se trabalharam os conceitos de Produção, Consumo, Modelo de Produção e Consumo Industrial e suas relações com o contexto dos resíduos e rejeitos sólidos industriais no Brasil e em pólos de calçados brasileiros. Igualmente caracterizaram-se estes conceitos e os impactos ambientais decorrentes dos resíduos e rejeitos como partes do mesmo fenômeno. Também se verificou que o emprego, ou não, de métodos e técnicas de gerenciamento depende dos valores da cultura empresarial predominante no setor. Além disso, atuam como fator limitante desse procedimento o custo da logística; a implantação incipiente do conceito de consórcio de empresas, para seu tratamento. Nos pólos brasileiros de calçados analisados a periculosidade dos seus resíduos e rejeitos é semelhante à dos demais ramos industriais do país. $\mathrm{E}$ o conceito de valorização é aplicado com maior ênfase nos pólos de Birigui (SP), Nova Serrana (MG) e Novo Hamburgo (RS). Fato este provavelmente ligado ao rigor da legislação local, estágio de fiscalização ambiental e mobilização dos atores interessados na solução da problemática social, ambiental e econômica desses materiais.

Palavras chave: Modo de produção e consumo industrial. Resíduos e rejeitos sólidos industriais. Pólos calçadistas do Brasil.

\section{RESUMEN}

\section{GESTIÓN DE LOS RESÍDUOS Y DESECHOS SÓLIDOS INDUSTRIALES: LA COYUNTURA DE LOS POLOS ZAPATEROS BRASILEÑOS}

En este estudio se trabajó los conceptos de la Producción, del Consumo y del Modo de Producción y Consumo Industrial y sus relaciones con el contexto de los residuos y desechos sólidos industriales en Brasil y pólos brasileños de calzado. Igualmente fue caracterizado estos conceptos y los impactos ambientales de los resíduos y desechos como parte de un mismo fenómeno. También fue verificado que el uso o no de métodos y técnicas de manejo depende de los valores de la cultura corporativa que prevalecen en el sector. Además, actúa como un factor limitante en este procedimiento el coste de la logística, la aplicación incipiente del concepto de consorcio de empresas para su tratamiento. En los polos de calzado brasileño se encontró la peligrosidad de sus residuos y desechos es similar a la de otras industrias del país y el concepto de valoración se aplica con mayor énfasis en el pólo de Birigui (SP), Nova Serrana (MG) y Novo Hamburgo (RS). Este hecho está probablemente relacionado à los rigores de las leyes locales, la etapa de monitoreo ambiental 
y la movilización de los interesados en la solución de los problemas sociales, ambientales y económicos de estos materiales.

Palabras clave: Modo de la producción industrial y el consumo. Resíduos y desechos sólidos industriales. Polos de calzado en Brasil.

\section{INTRODUÇÃO}

O presente estudo descreve aspectos básicos da gestão de resíduos da indústria no Brasil e, particularmente, em três pólos industriais de calçados brasileiros como partes que são do Modo de Produção e Consumo capitalista, com destaque para a realidade da gestão de resíduos e rejeitos. Inicialmente são trabalhadas as definições dos termos produção e consumo e depois os de resíduos e rejeitos sólidos industriais, também gerados na produção de calçados, os quais contextualizam o tema pesquisado. Cumpre esclarecer que as particularidades do capitalismo não foram aqui consideradas.

Quanto ao objetivo este trabalho encerrou a caracterização da geração e destinação de resíduos e rejeitos da indústria brasileira, com foco particular aos da produção de calçados nos pólos de Birigui (SP), Franca (SP), Nova Serrana (MG) e Novo Hamburgo (RS).

Justifica esta pesquisa o fato de a indústria brasileira sofrer os impactos da crise capitalista ambiental, como parte que é do seu Modo de Produção e Consumo.

Já o problema deste estudo está idealizado pelas seguintes perguntas: 1) quais as definições dos conceitos de Produção e Consumo? e 2) Qual a relação do $\mathrm{MPCl}$ e o contexto dos resíduos sólidos industriais no Brasil e nos pólos brasileiros de calçados?

No que se refere ao método de abordagem do tema, se utilizou o materialismo dialético em que prevalece a idéia materialista do mundo da natureza. Neste caso a matéria vem em primeiro lugar; todos os fenômenos, objetos e processos são matéria; a consciência vem em segundo lugar como produto da matéria que admite o mundo nela refletir (TRIVIÑOS, 1987). Quanto às fontes bibliográficas de fundamentação do seu conteúdo o autor utilizou livros, teses e artigos publicados na rede internacional de computadores.

O MPCI E O CONTEXTO DOS RESÍDUOS SÓLIDOS INDUSTRIAIS (RSI) NO BRASIL E EM PÓLOS BRASILEIROS DE CALÇADOS

\section{O MPCI NO BRASIL}

Neste tópico são utilizadas as definições Produção e Consumo e sua relação com o $\mathrm{MPCl}$, o qual surge na Inglaterra, no final do século XVIII, como resultado da acumulação de capital e de avanços tecnológicos da expansão capitalista denominada Mercantilismo (VIEIRA, 2002). O MPCI significa o emprego de formas e processos de empregar capital na fabricação de bens por meio de máquinas, interferir na difusão de informações, controlar o mercado, e a organização de trabalho, em nível local e internacional. 
Deste modo, na análise do trabalho de Gomes (2008) pode-se inferir que não há produção sem consumo e vice versa, pois são dois processos interligados e interdependentes. Na análise do trabalho desse autor infere-se que o conceito de Produção é parte das atividades humanas e pode ser definido como um processo de transformação dos recursos naturais ou produtos já criados pelo homem para atender as suas necessidades, básicas e ou supérfluas, que ao mesmo tempo são contínuas e influem na produção. Já, o conceito de Consumo se apresenta sob três características: 1) consumo final, também chamado de consumo individual ou pessoal é o que o homem concretiza ao utilizar produtos como alimentos, calçados, vestuário etc., inclusive bens e serviços, oferecidos no mercado; 2) consumo produtivo como ferramentas, máquinas, meios de transporte etc. são integrados em novos produtos que virão a ser produzidos e consumidos posteriormente; 3) consumo coletivo consiste no uso de bens e serviços como escolas, comunidades, instituições de proteção social, justiça, estradas, entre outros.

O autor também admite que o excesso de produção (superprodução) ou consumo (procura) insuficiente pode provocar desequilíbrio na relação entre os dois processos, levando a crises sociais, ambientais e econômicas.

Entre os conceitos de Consumo citados o que interessa ao presente estudo é o de Consumo final, ou pessoal, devido sua relação direta com a geração e destinação de resíduos e rejeitos sólidos.

Em seu funcionamento o MPCI influencia a Divisão Internacional do Trabalho (DIT) que, por sua vez, submete os países às condicionantes deste modelo em nível internacional, e por efeito, às desigualdades socioeconômicas e aos problemas ambientais, inclusive provocados pelo manejo errados dos resíduos e rejeitos.

O espaço geográfico ocupado pelo $\mathrm{MPCl}$ no Brasil é predominante no triângulo formado por Belo Horizonte, Rio de Janeiro e São Paulo, na Região Sudeste. As indústrias alimentar, automobilística, metalúrgica, mecânica, mineral (não metálicos), petroquímica, química, têxtil, e de vestuário estão instaladas neste trecho do território brasileiro. Mas a maior densidade industrial está nas Regiões Metropolitanas de São Paulo, Campinas, Santos e nas cidades de Jundiaí, São José dos Campos, Sorocaba e Vale do Paraíba (GALVÃO, 1991, CAROLINE, 2012).

\section{CONTEXTOS DOS RSI’S NO BRASIL E EM PÓLOS BRASILEIROS DE CALÇADOS}

\section{NO BRASIL}

O RSI é conceituado como:

todo resíduo que resulte de atividades industriais e que se encontre nos estados sólido, semi-sólido, gasoso - quando contido, e líquido - cujas particularidades tornem inviável seu lançamento na rede pública de esgoto ou em corpos d'água, ou exijam para isso soluções técnica e economicamente inviáveis em face da melhor tecnologia disponível (CONAMA, 2002).

Para a finalidade do presente estudo a caracterização do contexto dos RSI's no Brasil a seguir demonstrada foi obtida do trabalho de Paixão et. al (2011): (i) a produção e o consumo de 
bens uma vez aumentados igualmente promove o acréscimo quantitativo e qualitativo da geração de resíduos e rejeitos, sendo estes últimos caracterizados como materiais que não oferecem condições técnicas ou econômicas de reciclagem ou reuso; (ii) a classificação do RSI em perigosos, não perigosos e inertes e a estocagem segura de amostras deve obedecer as normas NBR 10004 a NBR 10007; (iii) a responsabilidade pelo tratamento e destinação dos resíduos e rejeitos sólidos industriais é da fonte geradora conforme a Política Nacional de Resíduos Sólidos - PNRS (Lei no 12.305/2010); (iv) um inventário realizado em 2003 entre 13 estados brasileiros, distribuídos pelas 5 macro-regiões, apontou que são gerados anualmente 97.655.438, dos quais 3.786 .391 e 93.869.046 toneladas, respectivamente de resíduos e rejeitos perigosos e não perigosos (não inertes e inertes); (v) a indústria brasileira ante ao gerenciamento de resíduos e rejeitos está distribuída nas seguintes condutas: negligente (não se preocupa com o tratamento ou destinação correta seus resíduos e rejeitos), cautelosa (passiva, mas reativa quando fiscalizada), responsável (adota a qualidade ambiental); (vi) a Confederação Nacional das Indústrias faz a gestão da Rede de Resíduos e do Sistema Integrado de Bolsas de Resíduos (base de dados eletrônica de compra, venda, troca e doação de resíduos); (vii) entre os métodos de tratamento ou destinação final foram encontrados: armazenamento em tambor ou bombona, em área coberta ou descoberta; ração animal; destinação na própria indústria (incorporação no solo); aterro industrial próprio ou de terceiros; lixão público e particular; queima a céu aberto; co-processamento; lagoa sem impermeabilização; incinerador; incorporação no solo agrícola; rede de esgoto; reprocessamento; sucateiro; utilização em caldeira; reutilização, reciclagem e recuperação; fertirrigação; e sem destino definido; (viii) as barreiras para o tratamento e a destinação correta dos RSI's são, principalmente, a conduta (valores) e o comportamento (ações e ou omissões) empresarial; o custo de transporte devido a distância das unidades de tratamento em relação aos pólos industriais; o alto custo da logística reversa; a dificuldade de financiamento de sistemas de tratamento (equipamentos, máquinas, usinas etc.); a falta de dinheiro para recuperar áreas contaminadas; a baixa implantação do conceito de consórcio de pequenas e médias empresas, definido na PNRS, para tratamento de resíduos e rejeitos industriais.

\section{EM PÓLOS BRASILEIROS DE CALÇADOS}

O Brasil têm 7 pólos principais de fabricação de calçados distribuídos em 3 macro regiões (Sul, Sudeste e Nordeste) do seu território conforme Figura 1. 


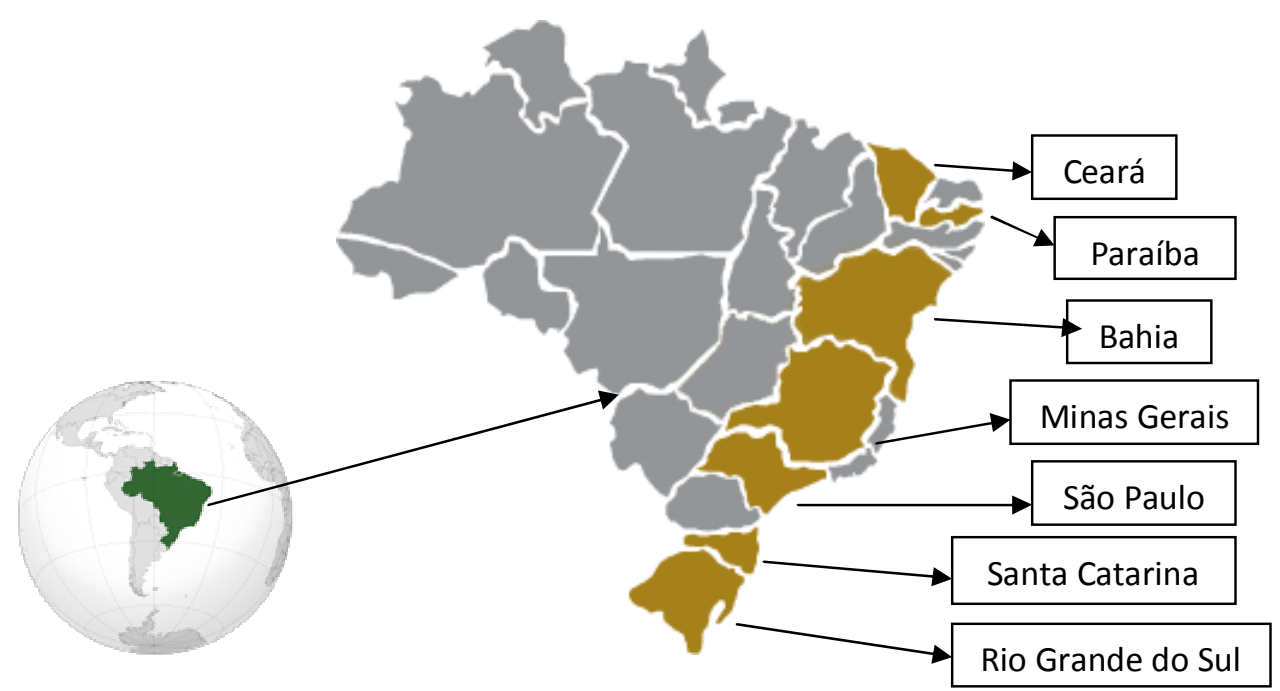

Figura 1. Pólos de fabricação de calçados. Fonte: Abicalçados (2012)

\section{Rio Grande do Sul}

Os principais pólos calçadistas estão em cidades localizadas no Vale do rio dos Sinos (cidades de Sapiranga, Campo Bom, Dois Irmãos, Ivoti e Novo Hamburgo); Vale do rio Paranhana (cidades de Igrejinha, Lindolfo Collor, Morro Reuter, Parobé, Presidente Lucena, Riozinho, Rolante, Santa Maria do Herval, Taquara, Igrejinha e Três Coroas), e Serra Gaúcha (cidades de Bento Gonçalves, Canela, Gramado, Caxias do Sul, Farroupilha, Nova Petrópolis, Nova Prata e Veranópolis). Nestes pólos se destacam a produção de calçados femininos com foco na qualidade, mas também se produzem calçados masculinos (ABICALÇADOS, 2012).

\section{Santa Catarina}

Conforme se constatou no trabalho de Frasseto (2012), o setor de calçados em Santa Catarina se concentra em dois pólos dedicados principalmente à produção de sapatos femininos: um na região Centro-litoral (cidades de São João Batista, Nova Trento, Canelinha e Major Gercino) e, o outro, no Sul do estado (cidades de Araranguá, Meleiro e Sombrio).

\section{São Paulo}

Os pólos calçadistas se concentram em quatro micro-regiões do Estado. O pólo de Franca destina-se à fabricação de calçado masculino; o de Birigui calçado infantil; e o de Jaú calçado feminino; o de Santa Cruz do Rio Pardo botas e sapatos estilo country e casual (ABICALÇADOS, 2012). 


\section{Minas Gerais}

Os dados que se seguem foram transcritos do Plano de Desenvolvimento do APL Calçadista de Nova Serrana (PDACNS, 2007) no qual se verificou que a atividade calçadista concentra-se em quatro micro-regiões: Belo Horizonte (calçado feminino); Nova Serrana (calçados esportivos), Juiz de Fora (calçado feminino) e Uberaba (calçado esportivo).

Bahia

Segundo a ABICALÇADOS (2012) as indústrias de calçados neste Estado (inclui as de bolsas, cintos e carteiras) estão distribuídas nas micro-regiões de Feira de Santana, Alagoinhas, Cruz das Almas, Itabuna, Vitória da Conquista e Ilhéus.

Paraíba

Este pólo é formado por Campina Grande, Patos, João Pessoa, Santa Rita, Bayex, Guarabira, Catolé do Rocha e Sousa no qual se destaca a produção de sandálias com matérias-primas sintéticas (ABICALÇADOS, 2012).

Ceará

A produção de calçados neste Estado abrange 3 pólos dedicados sobretudo à fabricação de sandálias de EVA e chinelos: Cariri (cidades de Crato, Juazeiro do Norte e Barbalha; Fortaleza (cidades de Fortaleza, Maranguape e Horizonte); e Sobral (ABICALÇADOS, 2012).

Quanto ao contexto dos resíduos sólidos da indústria calçadista brasileira este estudo resulta de dados bibliográficos e das observações do autor por ocasião das visitas técnicas realizadas nos pólos de Birigui e Franca no Estado de São Paulo, Nova Serrana, no Estado de Minas Gerais e Novo Hamburgo no Rio Grande do Sul.

Resumidamente pode-se dizer que as indústrias de calçados desses pólos, apesar de terem diferenças no uso de matérias-primas e na produção de tipos de calçados, geram praticamente as mesmas tipologias de resíduos e rejeitos em quantidade e qualidade proporcional aos volumes de calçados produzidos (VIEGAS, 1997). Ou seja, suas unidades industriais têm em comum a geração de resíduos e rejeitos perigosos (aparas de couro ou material sintético, restos de tintas, adesivos com solvente a base de hidrocarbonetos, espumas, estopas, panos e pincéis sujos com restos de produtos químicos); não inertes (papel, papelão, plástico, metais, retalhos de materiais sintéticos etc.); e inertes (vidro, espuma etc. não contaminados por produtos químicos). Num dos pólos do Rio Grande do Sul (Vale dos Sinos), estas tipologias de resíduos e rejeitos levantadas em 66 fábricas, segundo o autor antes citado, estão assim distribuídas quantitativamente: $30 \%$ perigosos; $37 \%$ não inertes; e $33 \%$ inertes.

Quanto à gestão dos resíduos e rejeitos a indústrias dos pólos visitados pelo autor tem comportamentos diferentes, mas podem ser enquadradas numa escala que vai de cautelosa a responsável (PAIXÃO et. al, 2011). É necessário ressaltar que do ponto de vista do modelo de gestão ambiental com foco na valorização dos resíduos e rejeitos gerados, ou melhor, da reutilização e reciclagem, o gerenciamento adotado nas indústrias dos pólos de Birigui, Nova Serrana e Rio Grande do Sul (Vales dos rios Sinos e Pacanhana) está mais para o comportamento responsável. Já o comportamento cauteloso caracteriza melhor as indústrias calçadistas de Franca 
devido empregar, majoritariamente, o foco no aterro sanitário. Todavia, o comportamento negligente também está presente, em pequena escala, em todos os pólos visitados pelo autor.

\section{CONSIDERAÇÕES FINAIS}

Neste trabalho se evidenciou que a Produção e o Consumo são dois processos interligados e interdependentes e envolvem questões sociais, ambientais e econômicas. Também constituem as faces do $\mathrm{MPCl}$ que determina a Divisão Internacional do Trabalho (DIT), assim como submete os países a este modelo, cuja reprodução impõe desigualdades socioeconômicas e problemas ambientais. A DIT é a sigla de um conceito empregado para se referir à especialização das atividades econômicas entre países e regiões em que uns e umas geralmente exportam tecnologia, empresas e empréstimos e outros exportam produtos industrializados e ou matériasprimas [ou só as últimas]. Vale destacar que o espaço geográfico em que predomina o $\mathrm{MPCl}$ no Brasil é composto pelos estados da Região Sudeste.

O contexto dos RSI's abrange as oscilações do equilíbrio entre a Produção e o Consumo; a sua gestão prevê o uso de normas técnicas para classificação e a destinação final por conta da fonte geradora.

Um levantamento parcial, de 9 anos atrás (2003), apontou que as indústrias brasileiras amostradas geraram mais de 97 milhões de toneladas anuais de resíduos e rejeitos sólidos e no seu armazenamento e destinação são empregadas 24 métodos e técnicas diferentes, inclusive sem destino definido. Também existe um banco de dados eletrônicos, denominado bolsa de resíduos, destinado a compra, venda, troca, doação etc. desses materiais.

Também se verificaram que ante ao destino dos seus resíduos e rejeitos as empresas não tem um comportamento único, pois entre elas estão presentes os modos negligente, cauteloso e responsável de destinar esses materiais. Este fato pode estar associado a valores da sua cultura empresarial; ao custo de transporte e destinação em unidades de tratamento e ou da logística reversa; a dificuldade de financiamento de sistemas de tratamento; a falta de dinheiro para recuperar áreas contaminadas; o desconhecimento do conceito de consórcio de pequenas e médias empresas para tratamento dos RSI's.

No que se refere aos pólos brasileiros de calçados de Birigui (SP), Franca (SP), Nova Serrana (MG) e Novo Hamburgo (RS) se verificou que os resíduos e rejeitos neles gerados tem as mesmas características dos de outros ramos industriais quanto à periculosidade. Ou seja, são enquadrados nas categorias: perigoso e não perigoso. E, considerando a valorização dos RSI's do ramo calçadista os pólos de Birigui (SP), Nova Serrana (MG) e Novo Hamburgo (RS) adotam métodos e técnicas ambientais mais adequadas (reuso, reciclagem etc.) que o de Franca (aterro sanitário). Uma das explicações para a diferença metodológica de gerenciamento entre os pólos pode estar relacionada ao estágio de mobilização dos empresários e demais atores de interesse para solucionar a problemática social, ambiental e econômica desses materiais. A legislação e a atuação 
dos órgãos estaduais de fiscalização ambiental também contribuem para chamar a atenção das fontes geradoras quanto à obrigação de destinar corretamente os RSI's.

BIBLIOGRAFIA

ABICALÇADOS. Pólos produtores. Disponível em:<http://www.abicalcados.com.br>. Acesso em: 14 out. 2012.

CONAMA - CONSELHO NACIONAL DO MEIO AMBIENTE. Resolução no 313, de 29 de outubro de 2002. Dispõe sobre o Inventário Nacional de Resíduos Sólidos Industriais. Ministério do Meio Ambiente, 2002.

FRASSETO, L. L. A indústria de calçados de São João Batista (SC): caracterização do sistema de produção. Disponível em: <http://www.cse.ufsc.br>. Acesso em: 14 out. 2012.

GALVÃO, O. J. A. Concentração industrial no Brasil segundo os censos 1907-1980. Revista Análise econômica. Ano 9. № 15. Março 1991, p. 143-181.

GOMES, C. Antecedentes do capitalismo. Disponível em: <http://www.eumed.net>. Acesso em: 13 out 2012.

PAIXÃO, J. F; ROMA, J. C.; MOURA, A. M. M. Cadernos de diagnóstico - resíduos sólidos industriais. Brasília: MMA, 2011.

PDACNS - Plano de Desenvolvimento do APL Calçadista de Nova Serrana. Belo Horizonte: SEBRAE/SINDINOVA/IEL, 2007

POCHMANN, M. Economia global e a nova Divisão Internacional do Trabalho. Disponível em: <http://decon.edu.uy>. Acesso em: 14 out. 2012.

VIEGAS, C. V. Capacidade tecnológica e gestão de resíduos sólidos industriais: estudo de caso em empresas calçadistas do Vale dos Sinos. Dissertação (Mestrado em Administração). 113 f. Universidade Federal do Rio Grande do Sul. Porto Alegre, UFRS, 1997.

VIEIRA, E. A. A questão ambiental do resíduo/lixo em Ribeirão Preto (SP). Dissertação (Mestrado em Geografia). 153f. 2002. Universidade Estadual Paulista. 